\title{
Bronchodilator delivery by metered-dose inhaler in mechanically ventilated COPD patients: influence of flow pattern
}

\author{
E. Mouloudi, G. Prinianakis, E. Kondili, D. Georgopoulos
}

Bronchodilator delivery by metered-dose inhaler in mechanically ventilated COPD patients: influence of flow pattern. E. Mouloudi, G. Prinianakis, E. Kondili, D. Georgopoulos. (C) ERS Journals Ltd 2000.

ABSTRACT: In mechanically ventilated patients the flow pattern during bronchodilator delivery by metered-dose inhaler (MDI) could be a factor that might influence the effectiveness of this therapy. In order to test this the effect of two different inspiratory flow patterns on the bronchodilation induced by $\beta_{2}$-agonists administered via MDI and spacer in a group of mechanically ventilated patients with chronic obstructive pulmonary disease (COPD) was examined.

Eighteen mechanically ventilated patients with COPD, were prospectively randomized to receive two $(n=8$, protocol $A)$ or six $(n=10$ protocol $B)$ puffs salbutamol $\left(100 \mu \mathrm{g} \cdot\right.$ puff $\left.^{-1}\right)$ either under pressure control (decelerating flow pattern) or under volume control (square wave flow pattern). With both modes, tidal volume and inspiratory time were identical. Salbutamol was administered via an MDI adapted to the inspiratory limb of the ventilator circuit using an aerosol cloud-enhancer spacer. After a 6-h washout, patients were crossed over to receive the same dose of salbutamol $(200$ or $600 \mu \mathrm{g}$, respectively in protocols $A$ and $B)$ by the alternative mode of administration. Static and dynamic airway pressures, minimum (Rint) and maximum $(R r s)$ inspiratory resistance and the difference between $R \operatorname{rs}$ and $R$ int $(\Delta R)$ were measured before and at 15,30 and $60 \mathrm{~min}$ after salbutamol.

Independent of the dose, salbutamol caused a significant decrease in dynamic and static airway pressures, $R$ int and $R$ rs. These changes were not influenced by the inspiratory flow pattern and were evident at 15,30 and 60 min after salbutamol.

It is concluded that salbutamol delivered via metered dose inhaler and spacer device, induces significant bronchodilation in mechanically ventilated patients with chronic obstructive pulmonary disease, the magnitude of which is not affected by the inspiratory flow/time profile.

Eur Respir J 2000; 16: 263-268.
Intensive Care Unit University Hospital of Heraklion, University of Crete, Heraklion, Crete, Greece

Correspondence: D. Georgopoulos, Intensive Care Unit, University Hospital of Heraklion, P.O. Box 1352, Heraklion 71110 , Heraklion Crete Greece Fax: 3081392636

Keywords: Inspiratory resistance respiratory system mechanics salbutamol

Received: June 201999

Accepted after revision April 112000
The delivery of bronchodilators via metered-dose inhalers (MDIs) in mechanically ventilated patients has received considerable interest in recent years [1-5]. It has been shown that MDIs adapted to the inspiratory line of the ventilator using a spacer device are as effective as nebulizers, despite the significantly lower dose of bronchodilator given by MDI [1-5]. A spacer device is thought to be fundamental to demonstrating the efficacy of the bronchodilatory therapy given by MDI [1-5]. Studies that delivered bronchodilators via MDI directly to the endotracheal tube failed to demonstrate any beneficial effect even after administration of high doses of bronchodilators [6]. The use of MDIs has several advantages over use of nebulizers, such as reduced cost, ease of administration, less personnel time, reliability of dosing and lower risk of contamination [7-10].

The technique of administration of bronchodilators in mechanically ventilated patients using an MDI and a spacer is an important factor determining the efficacy of this therapy. The timing of drug delivery and ventilator parameters during the administration of bronchodilators, such as the tidal volume $(V \mathrm{~T})$, inspiratory flow/time profile and end-inspiratory pause (breath-hold), have been suggested to influence drug delivery to target sites and, thus, bron- chodilation $[4,5,11,12]$. These suggestions, however, are based on in vitro studies using models of mechanical ventilation. Indeed it was recently demonstrated in mechanically ventilated patients with chronic obstructive pulmonary disease (COPD) that application of an end-inspiratory pause time of $5 \mathrm{~s}$ or a $50 \%$ increase in $V \mathrm{~T}$ when bronchodilators were administered in adequate doses did not have any additional bronchodilator effect $[13,14]$. These studies raise the issue that ventilator settings may not be a critical factor in bronchodilation. The present study was undertaken in order to investigate further the influence of ventilator settings on drug-induced bronchodilation. Specifically, the purpose of the present study was to examine the effect of inspiratory flow/time profile on the bronchodilation induced by $\beta_{2}$-agonists administered via MDI and spacer in a homogeneous group of mechanically ventilated patients with COPD.

\section{Methods}

Eighteen patients (13 males and five females) with COPD, requiring mechanical ventilation for the management of acute respiratory failure due to an acute exacerbation of chronic airflow obstruction, were studied. All 
patients had a previous diagnosis of COPD and met established criteria for this diagnosis [15]. Patients with a diagnosis of bronchial asthma were excluded. The study was approved by the Hospital Ethics Committee and informed consent was obtained from the patients or their families.

The patients were studied in a semirecumbent position during a period of clinical stability 2-3 days after the onset of mechanical ventilation. All patients were intubated with an endotracheal tube of $8-9 \mathrm{~mm}$ in internal diameter, heavily sedated (propofol and fentanyl) and ventilated on volume-controlled mode using Servo 300 (Siemens. Solna, Sweden) ventilators. Confirmation of the absence of respiratory muscle activity was based on specific criteria, including absence of negative deflection of airway pressure $(P$ aw $)$, stabilization of $P$ aw waveform constancy of peak inspiratory pressure from breath to breath and exponential decline of expiratory flow [16]. The ventilator was set to deliver a specific $V \mathrm{~T}\left(8 \mathrm{~mL} \cdot \mathrm{kg}^{-1}\right)$ with a square wave flow/ time profile. Inspiratory flow was set to $0.55-0.65 \mathrm{~L} \cdot \mathrm{s}^{-1}$ and no end-inspiratory pause was applied. Minute ventilation was adjusted in each individual by the attending physician in order to maintain normal arterial $\mathrm{pH}$ and remained constant throughout the study. Because most of the patients had chronic elevation of arterial carbon dioxide tension $\left(\mathrm{Pa}, \mathrm{CO}_{2}\right)$, a normal $\mathrm{pH}$ resulted in hypercapnia (table 1). Hypercapnia was not corrected in order to avoid further increases in dynamic hyperinflation and posthypercapnic metabolic alkalosis. Extrinsic positive end-expiratory pressure (PEEP) was set to zero. The patients' physical characteristics and baseline ventilator settings are shown in table 1.

Flow at the airway opening was measured with a heated pneumotachograph (Hans-Rudolf3700; Hans-Rudolf, Kansas City, KS, USA) and a differential pressure transducer (Micro-Switch 140PC; Honeywell Ltd., Toronto, Ontario, Canada) placed between the endotracheal tube and the ventilator. Flow was electronically integrated to calculate volume. Paw were measured (Micro-Switch 140PC) from a side port between the pneumotachograph and the endotracheal tube. All signals were sampled at $50 \mathrm{~Hz}$ (Windaq Instruments, Inc., Akron, OH, USA) and stored on a computer disk for later analysis.

Patients were prospectively randomized to receive two (eight patients, protocol A) or six puffs (10 patients, protocol B) salbutamol $100 \mu \mathrm{g} \cdot$ puff $^{-1}$ given by an MDI canister (Aerolin inhaler, GlaxoWellcome, Evreux) with either pressure control or volume control. Thus the patients received a total dose of 200 and $600 \mu \mathrm{g}$ of salbutamol, respectively, in protocols $\mathrm{A}$ and $\mathrm{B}$. With volume control the ventilator settings were kept constant to baseline (table 1) whereas, with pressure control, the pressure level was set such as to achieve a $V \mathrm{~T}$ similar to that with volume control. Inspiratory time was kept constant. Therefore under both protocols, the variable that was manipulated during salbutamol administration was the inspiratory flow/time profile: the flow/time profile was square wave with volume control whereas it had a decelerating pattern with pressure control. After a 6-h washout, patients were crossed over to receive the drug (two or six puffs of salbutamol depending on the protocol) by the alternative mode of administration. The MDl canister was adapted to the inspiratory limb of the ventilator circuit using an aerosol cloud-enhancer (ACE) spacer (Diemolding Healthcare Division, Canastota, NY, USA), whereby the MDI flume is directed away from the patient. The spacer was placed just before the Y-ventilator connector. The canister was shaken before each series of puffs. Each actuation was performed at 20-30-s intervals, immediately before initiation of airflow by the ventilator. In the intervals, the patients were ventilated at baseline ventilator settings. All bronchodilators were withheld for $\geq 6 \mathrm{~h}$ before the study. All patients received corticosteroids ( $240 \mathrm{mg}$ methylprednisolone $\cdot$ day $^{-1}$ ) and this regimen was not modified during the study. None of the patients were on theophylline. Arterial blood gas levels were measured before drug administration. Arterial oxygen saturation $\left(\mathrm{S}_{\mathrm{a}} \mathrm{O}_{2}\right)$ was measured continuously using a pulse oximeter (Critikon, Tampa, FL, USA).

Respiratory system mechanics and cardiac frequency $(f \mathrm{C})$ were assessed before (baseline) and at 15, 30 and 60 min after each series of puffs. The mechanical properties of the respiratory system were determined while the patient was ventilated under volume control at the baseline ventilator settings shown in table 1 . The mechanics of the respiratory system were measured using the occlusion technique $[17,18]$. In brief, the airways were occluded for $5 \mathrm{~s}$ at end-inspiration and there was an immediate drop in $P$ aw from a peak to a lower value, followed by a gradual decay to a plateau. In each patient, at least five breaths with satisfactory plateaus were analysed and the mean values reported. Intrinsic PEEP (PEEPi) was measured by occluding the airways for 5-s at the end of a tidal expiration and observing the $P$ aw. Again, five breaths were analysed. Respiratory system static inflation endinspiratory compliance $(C$ rs,st $)$ and minimum $(R$ int $)$ and maximum $(R \mathrm{rs})$ resistance of the respiratory system were computed according to standard formulas $[17,18]$. The difference between $R$ rs and $R$ int $(\Delta \mathrm{R})$, caused by timeconstant inequalities and/or viscoelastic behaviour (stress relaxation), was also calculated. Rint and $R$ rs were corrected for the finite occlusion time of the occlusion valve of the ventilator [19]. The endotracheal tube resistance was not taken into account, because each patient served as their own control.

Data were analysed by paired t-test and two-way analysis of variance (ANOVA) for repeated measurements, where appropriate. When the F-value was significant,

Table 1. - Patient characteristics and baseline ventilator settings

\begin{tabular}{lccccccccc}
\hline Subjects n & Age yrs & $F \mathrm{I}, \mathrm{O}_{2} \%$ & $P_{\mathrm{a}, \mathrm{O}_{2}} \mathrm{mmHg}$ & $P_{\mathrm{a}, \mathrm{CO}_{2}} \mathrm{mmHg}$ & $V \mathrm{~T} \mathrm{~L}$ & $f \mathrm{R}$ breaths $\cdot \mathrm{min}^{-1}$ & $\mathrm{~V}^{\prime} \mathrm{I} \mathrm{L} \cdot \mathrm{s}^{-1}$ & $t \mathrm{I} / \mathrm{ttot}^{\prime}$ & $V^{\prime} \mathrm{E} \mathrm{L} \cdot \mathrm{min}^{-1}$ \\
\hline Protocol A & $70.6 \pm 10.8$ & $0.35 \pm 0.05$ & $68.0 \pm 4.8$ & $57.5 \pm 8.0$ & $0.50 \pm 0.08$ & $10.3 \pm 0.5$ & $0.58 \pm 0.02$ & $0.27 \pm 0.06$ & $5.24 \pm 0.3$ \\
Protocol B & $70.0 \pm 6.6$ & $0.38 \pm 0.07$ & $75.8 \pm 7.8$ & $62.3 \pm 8.2$ & $0.54 \pm 0.06$ & $11.1 \pm 0.9$ & $0.60 \pm 0.02$ & $0.22 \pm 0.02$ & $5.91 \pm 0.5$ \\
\hline
\end{tabular}

Data are presented as mean \pm SD. $F \mathrm{I}_{1} \mathrm{O}_{2}$ : fractional concentration of inspired oxygen. $P \mathrm{a}, \mathrm{O}_{2}, P \mathrm{a}, \mathrm{CO}_{2} ;$ partial pressure of arterial oxygen and carbon dioxide, respectively; $V \mathrm{~T}$ : tidal volume; $f \mathrm{R}$; respiratory frequency; $V^{\prime} \mathrm{I}$ : constant inspiratory flow; tI/ttot: duty cycle; $V^{\prime} \mathrm{T}$ : minute ventilation. $(1 \mathrm{mmHg}=0.133 \mathrm{kPa}$. $)$ 
Table 2. - Protocol A. Airway pressures, respiratory system mechanics ${ }^{+}$and cardiac frequency ( $f$ c) before and after 200 $\mu \mathrm{g}$ (two puffs) salbutamol given with constant (volume control) and decelerating (pressure control) flow pattern

\begin{tabular}{|c|c|c|c|c|c|c|c|c|}
\hline & \multicolumn{4}{|c|}{ Volume control } & \multicolumn{4}{|c|}{ Pressure control } \\
\hline & Baseline & $15 \mathrm{~min}$ & $30 \mathrm{~min}$ & $60 \mathrm{~min}$ & Baseline & $15 \mathrm{~min}$ & $30 \mathrm{~min}$ & $60 \mathrm{~min}$ \\
\hline$P$ pk $\mathrm{cmH}_{2} \mathrm{O}$ & $30.4 \pm 3.8$ & $26.6 \pm 4.6^{*}$ & $26.4 \pm 4.6^{*}$ & $26.4 \pm 4.6^{*}$ & $30.8 \pm 4.7$ & $26.8 \pm 5.2 *$ & $26.8 \pm 5.2 *$ & $27.4 \pm 5.2 *$ \\
\hline$P 1 \mathrm{cmH}_{2} \mathrm{O}$ & $17.8 \pm 3.6$ & $15.9 \pm 4.0^{*}$ & $15.7 \pm 4.1 *$ & $15.7 \pm 4.1^{*}$ & $18.2 \pm 4.8$ & $16.3 \pm 4.7^{*}$ & $16.1 \pm 4.9^{*}$ & $16.2 \pm 4.7 *$ \\
\hline$P \mathrm{pmH}_{2} \mathrm{O}$ & $14.7 \pm 3.8$ & $12.9 \pm 4.0 *$ & $12.8 \pm 4.2 *$ & $12.7 \pm 4.2^{*}$ & $15.2 \pm 5.0$ & $13.3 \pm 4.8^{*}$ & $13.1 \pm 4.9 *$ & $13.1 \pm 4.9 *$ \\
\hline$R$ int $\mathrm{cmH}_{2} \mathrm{O} \cdot \mathrm{L}^{-1} \cdot \mathrm{s}$ & $21.0 \pm 2.4$ & $17.9 \pm 3.3 *$ & $17.9 \pm 2.6^{*}$ & $17.9 \pm 2.6^{*}$ & $21.2 \pm 3.3$ & $17.6 \pm 3.2 *$ & $17.9 \pm 2.6$ & $18.5 \pm 2.9^{*}$ \\
\hline$R \mathrm{rs} \mathrm{cmH}_{2} \mathrm{O} \cdot \mathrm{L}^{-1} \cdot \mathrm{s}$ & $26.3 \pm 2.9$ & $22.8 \pm 3.6^{*}$ & $22.8 \pm 2.7 *$ & $22.8 \pm 2.7$ & $26.3 \pm 2.9$ & $22.4 \pm 3.3^{*}$ & $22.8 \pm 2.8^{*}$ & $23.7 \pm 3.2 *$ \\
\hline$\Delta R \mathrm{cmH}_{2} \mathrm{O} \cdot \mathrm{L}^{-1} \cdot \mathrm{s}$ & $5.3 \pm 1.0$ & $4.9 \pm 0.8$ & $4.9 \pm 0.8$ & $4.9 \pm 0.8$ & $5.2 \pm 1.1$ & $4.9 \pm 0.8$ & $4.9 \pm 0.9$ & $5.2 \pm 1.0$ \\
\hline$C_{\text {rs,st }} \mathrm{cmH}_{2} \mathrm{O} \cdot \mathrm{L}^{-1}$ & $60.8 \pm 16.7$ & $63.0 \pm 21.8$ & $64.8 \pm 21.6$ & $64.5 \pm 21.5$ & $63.2 \pm 23.9$ & $65.2 \pm 25.3$ & $66.0 \pm 25.1$ & $66.2 \pm 25.1$ \\
\hline PEEPi $\mathrm{cmH}_{2} \mathrm{O}$ & $5.5 \pm 1.8$ & $3.8 \pm 1.2^{*}$ & $3.8 \pm 1.2 *$ & $3.8 \pm 1.2 *$ & $5.9 \pm 2.3$ & $4.2 \pm 1.9 *$ & $4.1 \pm 1.8^{*}$ & $4.1 \pm 1.3^{*}$ \\
\hline$f \mathrm{C}$ beats $\cdot \mathrm{min}^{-1}$ & $78.3 \pm 15.8$ & $78.9 \pm 16.8$ & $79.1 \pm 16.0$ & $79.8 \pm 17.3$ & $77.5 \pm 18.1$ & $79.0 \pm 18.3$ & $79.3 \pm 17.6$ & $78.8 \pm 17.1$ \\
\hline
\end{tabular}

Data are presented as mean $\pm \mathrm{SD} .{ }^{+}$: measured when the patients were on volume control with square wave inspiratory flow time profile. $P$ pk, $P 1, P$ p;: dynamic and static airway pressure at end inspiration (peak pressure, lower pressure and plateau pressure, respectively); $R$ int, $R$ rs: minimum and maximum resistance of the respiratory system, respectively; $\Delta R$ : difference between $R \mathrm{rs}$ and $R$ int; $C$ rs,st: respiratory system static inflation end-inspiratory compliance; PEEPi: intrinsic positive end-expiratory pressure. *: $\mathrm{p}<0.05$ versus baseline (two-way analysis of variance).

Tukey's test was used to identify significant differences. A p-value of $<0.05$ was considered statistically significant. Data are expressed as mean $\pm \mathrm{SD}$.

\section{Results}

Baseline respiratory system mechanics and $f C$ before the administration of each series of puffs (two or six) of salbutamol are shown in tables 2 and 3 . For any given protocol, there was no significant difference in any of these variables between the two conditions of drug delivery (ANOVA). Furthermore, independent of the protocol, baseline arterial blood gas levels did not differ significantly between the two modes of salbutamol administration. In protocol A, when two puffs salbutamol were administered with volume control, baseline arterial oxygen tension $\left(\mathrm{Pa}_{\mathrm{a}} \mathrm{O}_{2}\right)$ and $\mathrm{Pa}_{\mathrm{a}} \mathrm{CO}_{2}$ were $8.95 \pm 0.65$ (67.3 4 4.9 $\mathrm{mmHg})$ and $7.47 \pm 1.05 \mathrm{kPa}(56.2 \pm 7.9 \mathrm{mmHg})$ respectively, whereas the corresponding values with pressure control were $9.28 \pm 1.02(69.8 \pm 7.7 \mathrm{mmHg})$ and $7.93 \pm 1.32 \mathrm{kPa}$ $(59.6 \pm 9.9 \mathrm{mmHg})$ (paired t-test. $\mathrm{p}>0.05)$. In protocol $\mathrm{B}$, with volume control, baseline $P \mathrm{a}, \mathrm{O}_{2}$ and $\mathrm{Pa}, \mathrm{CO}_{2}$ were $10.1 \pm$ $0.95(76.3 \pm 7.2 \mathrm{mmHg})$ and $8.55 \pm 1.04 \mathrm{kPa}(64.3 \pm 7.8$
$\mathrm{mmHg}$ ) respectively, whereas, with pressure control, the corresponding values were $9.74 \pm 1.33(73.2 \pm 10.0 \mathrm{mmHg})$ and $8.18 \pm 1.16 \mathrm{kPa}(61.5 \pm 8.7 \mathrm{mmHg})$ (paired t-test $\mathrm{p}>$ 0.05 ). Similarly, baseline (before salbutamol administration) respiratory system mechanics and arterial blood gas levels did not differ during the $6 \mathrm{~h}$ of observation (paired ttest, $\mathrm{p}>0.05$ ). Specifically, in protocol A, the initial baseline values of $R$ int and $R$ rs were $20.6 \pm 2.9$ and $25.8 \pm 3.2$ $\mathrm{cmH}_{2} \mathrm{O} \cdot \mathrm{L}^{-1} \cdot \mathrm{s}$, respectively, whereas the corresponding values after $6 \mathrm{~h}$ were $20.8 \pm 2.3$ and $26.5 \pm 3.1 \mathrm{cmH}_{2} \mathrm{O} \cdot \mathrm{L}^{-1} \cdot \mathrm{s}$. In protocol B, the initial baseline $R$ int and $R$ rs were $18.8 \pm 3.5$ and $24.5 \pm 3.7 \mathrm{cmH}_{2} \mathrm{O} \cdot \mathrm{L}^{-1} \cdot \mathrm{s}$, respectively, whereas the corresponding values after $6 \mathrm{~h}$ were $17.5 \pm 3.6$ and $23.6 \pm 3.6$ $\mathrm{cmH}_{2} \mathrm{O} \cdot \mathrm{L}^{-1} \cdot \mathrm{s}$. Therefore, in both protocols, factors other than salbutamol did not appreciably affect lung function.

The mean pressure that achieved a $V \mathrm{~T}$ similar to that observed with volume control was $22.0 \pm 4.2$ and $31.2 \pm 4.6$ $\mathrm{cmH}_{2} \mathrm{O}$, respectively, in protocols $\mathrm{A}$ and $\mathrm{B}$. As expected, the flow/time profile, when salbutamol was administered with pressure control, differed substantially from that with volume control. Particularly during early inspiration, flow was considerably higher with pressure control than with volume control $\left(0.8 \pm 0.2\right.$ versus $0.58 \pm 0.02 \mathrm{~L} \cdot \mathrm{s}^{-1}$ in protocol

Table 3. - Protocol B. Airway pressures, respiratory system mechanics ${ }^{+}$and cardiac frequency ( $f$ ) before and after 600 $\mu \mathrm{g}$ (six puffs) salbutamol given with constant (volume control) and decelerating (pressure control) flow pattern

\begin{tabular}{|c|c|c|c|c|c|c|c|c|}
\hline & \multicolumn{4}{|c|}{ Volume control } & \multicolumn{4}{|c|}{ Pressure control } \\
\hline & Baseline & $15 \mathrm{~min}$ & $30 \mathrm{~min}$ & $60 \mathrm{~min}$ & Baseline & $15 \mathrm{~min}$ & $30 \mathrm{~min}$ & $60 \mathrm{~min}$ \\
\hline$P$ pk $\mathrm{cmH}_{2} \mathrm{O}$ & $35.9 \pm 4.7$ & $31.1 \pm 5.3 *$ & $31.7 \pm 4.6^{*}$ & $31.8 \pm 5.1 *$ & $35.3 \pm 5.3$ & $30.8 \pm 4.0 *$ & $30.8 \pm 4.5^{*}$ & $30.8 \pm 3.8^{*}$ \\
\hline$P 1 \mathrm{cmH}_{2} \mathrm{O}$ & $24.9 \pm 3.8$ & $22.3 \pm 4.1$ & $22.8 \pm 3.5$ & $23.0 \pm 4.1 *$ & $24.6 \pm 5.0$ & $22.1 \pm 3.5^{*}$ & $22.0 \pm 3.8 *$ & $22.0 \pm 3.0 *$ \\
\hline $\mathrm{Pp} \mathrm{cmH}_{2} \mathrm{O}$ & $21.5 \pm 3.0$ & $19.0 \pm 3.7 *$ & $19.6 \pm 3.2 *$ & $19.6 \pm 3.6^{*}$ & $20.9 \pm 4.0$ & $18.9 \pm 2.8^{*}$ & $18.9 \pm 3.3 *$ & $19.0 \pm 2.6^{*}$ \\
\hline$R$ int $\mathrm{cmH}_{2} \mathrm{O} \cdot \mathrm{L}^{-1} \cdot \mathrm{s}$ & $18.4 \pm 2.9$ & $14.8 \pm 2.9^{*}$ & $14.8 \pm 2.5^{*}$ & $14.8 \pm 2.5^{*}$ & $17.9 \pm 3.7$ & $14.5 \pm 3.4 *$ & $14.7 \pm 3.0^{*}$ & $14.7 \pm 3.1^{*}$ \\
\hline$R \mathrm{rs} \mathrm{cmH} 2 \mathrm{O} \cdot \mathrm{L}^{-1} \cdot \mathrm{s}$ & $24.0 \pm 3.7$ & $20.2 \pm 3.6^{*}$ & $20.2 \pm 3.3 *$ & $20.4 \pm 3.3 *$ & $24.1 \pm 3.6$ & $19.9 \pm 3.6^{*}$ & $20.0 \pm 3.2 *$ & $19.7 \pm 3.2 *$ \\
\hline$\Delta R \mathrm{cmH}_{2} \mathrm{O} \cdot \mathrm{L}^{-1} \cdot \mathrm{s}$ & $5.7 \pm 2.3$ & $5.4 \pm 2.1$ & $5.4 \pm 2.1$ & $5.7 \pm 1.8$ & $6.2 \pm 2.5$ & $5.4 \pm 2.1$ & $5.2 \pm 2.1$ & $5.0 \pm 2.0$ \\
\hline $\mathrm{Crs}_{\mathrm{r}, \mathrm{st}} \mathrm{cmH}{ }_{2} \mathrm{O} \cdot \mathrm{L}^{-1}$ & $44.6 \pm 12.6$ & $45.5 \pm 16.2$ & $43.2 \pm 13.4$ & $43.1 \pm 15.4$ & $45.3 \pm 15.8$ & $44.8 \pm 18.0$ & $44.2 \pm 18.7$ & $42.0 \pm 12.1$ \\
\hline PEEPi $\mathrm{cmH}_{2} \mathrm{O}$ & $8.7 \pm 2.5$ & $6.3 \pm 2.6^{*}$ & $6.4 \pm 2.6^{*}$ & $6.1 \pm 2.7^{*}$ & $8.0 \pm 1.9$ & $5.8 \pm 1.6^{*}$ & $5.5 \pm 1.8^{*}$ & $5.6 \pm 1.7 *$ \\
\hline$f \mathrm{C}$ beats $\cdot \min ^{-1}$ & $84.6 \pm 15.6$ & $89.2 \pm 16.6^{*}$ & $91.4 \pm 16.4 *$ & $90.5 \pm 16.6^{*}$ & $83.3 \pm 14.5$ & $87.3 \pm 16.1$ & $88.0 \pm 16.3 *$ & $87.9 \pm 17.1^{*}$ \\
\hline
\end{tabular}

Data are presented as mean $\pm \mathrm{SD} .{ }^{+}:$measured when the patients were on volume control with square wave inspiratory flow time profile. $P$ pk, $P 1, P$ p;: dynamic and static airway pressure at end inspiration (peak pressure, lower pressure and plateau pressure, respectively); $R$ int, Rrs: minimum and maximum resistance of the respiratory system, respectively; $\Delta R$ : difference between $R \mathrm{rs}$ and $R$ int; $C$ rs,st: respiratory system static inflation end-inspiratory compliance; PEEPi: intrinsic positive end-expiratory pressure. *: $\mathrm{p}<0.05$ versus baseline (two-way analysis of variance). 
A and $0.9 \pm 0.1$ versus $0.6 \pm 0.02 \mathrm{~L} \cdot \mathrm{s}^{-1}$ in protocol B). In all cases, inspiratory flow was still present when the ventilator switched from inspiration to expiration. With pressure control, inspiratory flow at the end of inspiration $(0.31 \pm 0.2$ and $0.38 \pm 0.1 \mathrm{~L} \cdot \mathrm{s}^{-1}$ respectively, in protocols $\mathrm{A}$ and $\mathrm{B}$ ) was significantly lower than that with volume control, which, by definition, was constant throughout inspiration.

The effects of salbutamol, administered with volume and pressure control, on respiratory system mechanics and $f \mathrm{C}$ are shown in tables 2 and 3. Independent of the dose of salbutamol, the inspiratory flow/time profile did not have any significant effect on the salbutamol-induced bronchodilation. With both modes of administration, two or six puffs salbutamol caused a significant decrease in dynamic and static airway pressures, Rint, Rrs and PEEPi (ANOVA). These effects were evident at $15 \mathrm{~min}$ after drug delivery and maintained relatively constant for $\geq 60 \mathrm{~min}$. Figures 1 and 2 show individual values of $R$ int at baseline and 60 min after 200 and $600 \mu \mathrm{g}$ of salbutamol, respectively, in protocols $\mathrm{A}$ and $\mathrm{B}$. In protocol $\mathrm{A}, f \mathrm{C}$ remained relatively constant throughout (table 2). In protocol B, independent of the mode of drug delivery, $f C$ increased slightly but significantly after salbutamol (table 3 ). For a given protocol, with both ventilator modes of drug administration, changes in $\Delta R$ and $C$ rs,st were not significant at any time interval after salbutamol administration. In both protocols, $\mathrm{Sa}_{\mathrm{a}} \mathrm{O}_{2}$ remained constant throughout the study, indicating that clinically significant changes in $\mathrm{Pa}, \mathrm{O}_{2}$ as a result of salbutamol administration did not occur.

Independent of the protocol, there was a significant linear relationship between the response of $R$ int to salbutamol administered with pressure and volume control (figs. 3 and 4), indicating that within patients the response to salbutamol was quite consistent and independent of the ventilator mode during drug administration. In protocol A, with both modes of drug administration, one patient did not respond to salbutamol and one exhibited bronchodilation only when the drug was given with volume control (figs. 1 and 3). In protocol B, in all but one patient, salbutamol caused a significant decrease in Rint that was

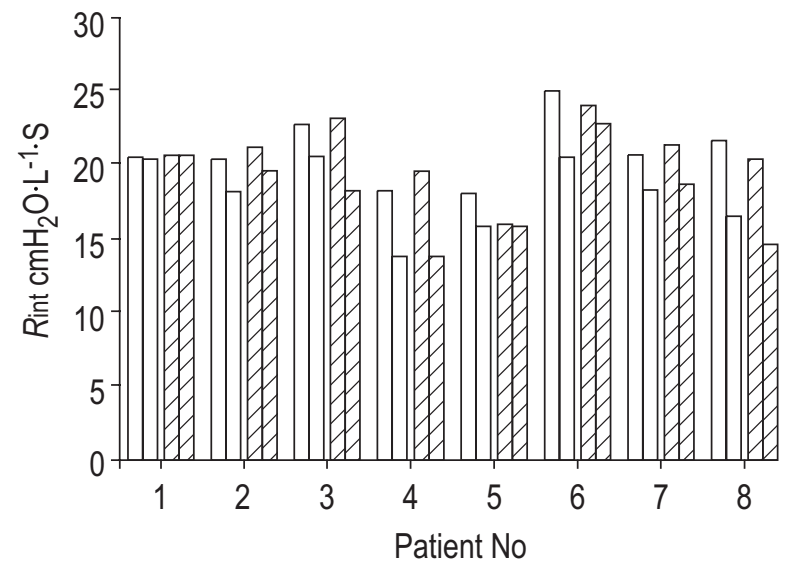

Fig. 1. - Protocol A. Individual values of minimum resistance of the respiratory system (Rint) before and $60 \mathrm{~min}$ after administration of 200 $\mu \mathrm{g}$ salbutamol. $\square$ : volume control; $\square$ : pressure control. For a given patient and mode of drug administration, the two bars represent $R$ int at time 0 (before salbutamol administration, baseline) and at $60 \mathrm{~min}$ after salbutamol administration. Rint at 15 and $30 \mathrm{~min}$ after salbutamol administration were omitted for clarity of presentation. very similar with volume and pressure control. In one patient, significant bronchodilation was observed only when salbutamol was given with volume control (figs. 2 and 4).

\section{Discussion}

The present work re-confirmed previous studies showing that, in mechanically ventilated patients with COPD, $\beta_{2}$-agonists delivered by MDI and spacer produced a significant and sustained decrease in inspiratory resistance [13]. It was further shown that the response was evident even when salbutamol was given in relatively low doses and not influenced by the inspiratory flow/time profile during drug delivery. Independent of the dose of salbutamol, $\Delta R$ remained relatively constant throughout the study, indicating that salbutamol acted by dilating the central airways, in line with previous observations $[3,13$, 14]. Although expiratory resistance was not measured in the present study, it was most probably decreased by salbutamol, as indicated by the significant reduction in PEEPi and end-inspiratory static plateau pressure, indirect indices of dynamic hyperinflation.

All patients were on corticosteroids, and this regimen remained unaltered during the study. The authors do not believe that the administration of corticosteroids influenced the results. The patients were on corticosteroids for $\geq 24 \mathrm{~h}$ before being studied (most of them, $>48 \mathrm{~h}$ ). It has been shown that administration of corticosteroids during acute exacerbation of COPD induces significant bronchodilation that reaches near maximum by $24 \mathrm{~h}$ [20]. This is also supported by the fact that baseline (before salbutamol) respiratory system mechanics and blood gas levels were stable during the $6 \mathrm{~h}$ of observation. Therefore, in these patients, lung function during the study period was not significantly affected by factors other than salbutamol.

In mechanically ventilated patients, the optimal ventilatory pattern during delivery of bronchodilators with MDI

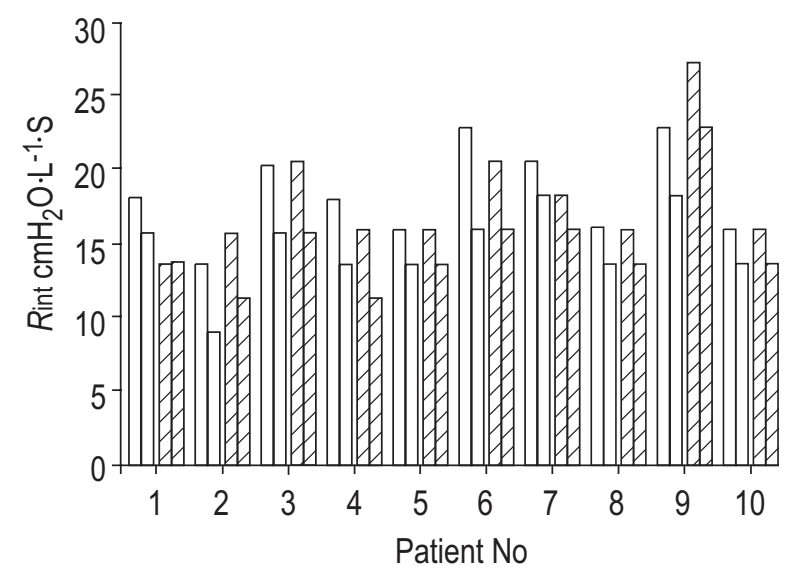

Fig. 2. - Protocol B. Individual values of minimum resistance of the respiratory system (Rint) before and $60 \mathrm{~min}$ after administration of 600 $\mu \mathrm{g}$ salbutamol. $\square$ : volume control; $\square$ : pressure control. For a given patient and mode of drug administration, the two bars represent Rint at time 0 (before salbutamol administration, baseline) and at $60 \mathrm{~min}$ after salbutamol administration. Rint at 15 and $30 \mathrm{~min}$ after salbutamol administration were omitted for clarity of presentation. 


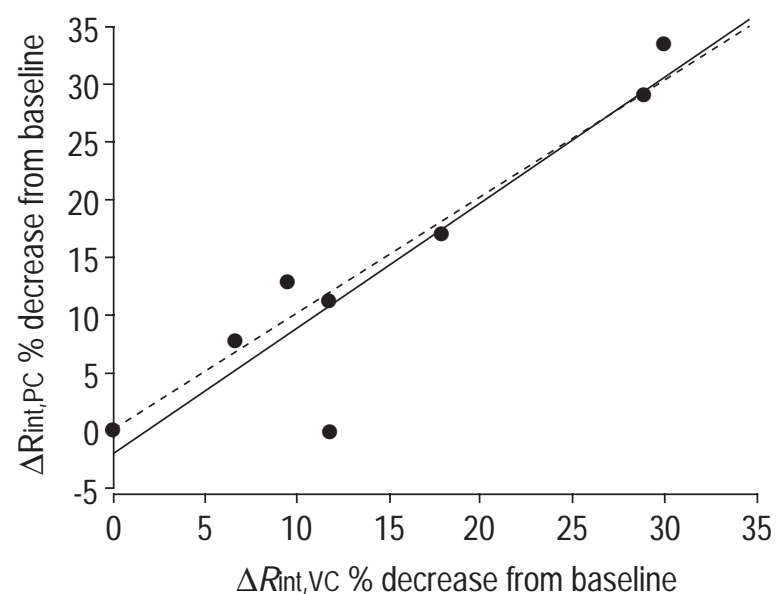

Fig. 3. - Protocol A. Relationship between the mean bronchodilatory response of minimum resistance of the respiratory system (Rint) $(\%$ decrease from baseline) when $200 \mu \mathrm{g}$ salbutamol were given with volume control (Rint,VC) and pressure control (Rint,PC). The mean bronchodilatory response was obtained by averaging the $R$ int response at 15,30 and $60 \mathrm{~min}$ after salbutamol. $\_$: regression line; - - - -: line of identity $(\mathrm{r}=0.92, \mathrm{p}<0.05)$. For clarity of presentation, the mean bronchodilatory response was used instead of data at various time intervals after drug administration. The significant linear relationships did not change when all data were pooled. $\Delta$ : change in.

and spacer is not well known. The use of low inspiratory flow, high $V \mathrm{~T}(>500 \mathrm{~mL})$, high duty cycle, decelerating rather than square-wave inspiratory/time profile and 3-5 $\mathrm{s}$ end-inspiratory pause has been suggested to increase the effectiveness of MDI therapy [4, 5, 11, 12]. However. these recommendations are based mainly on aerosol delivery data $[11,12]$, which may not reflect drug bronchodilator effect. Indeed, in recent studies, it was shown that neither application of a $5 \mathrm{~s}$ end-inspiratory pause nor increasing the $V \mathrm{~T}$, strategies which probably enhanced drug delivery $[4,5,11,12]$, augmented the bronchodilator effect of six puffs salbutamol $[13,14]$. The current study demonstrated that, at constant $V_{\mathrm{T}}$ and inspiratory time, changing the inspiratory flow/time profile did not have any effect on salbutamol-induced bronchodilation, given via MDI and spacer. This was true both with a low and high dose of the drug. It follows that significant bronchodilation can be achieved with both pressure or volume control and doses of salbutamol as low as $200 \mu \mathrm{g}$. The findings of the present work combined with those of previous studies do not support alterations in ventilator settings when bronchodilator drugs are administered in passively mechanically ventilated patients.

Two patients (one in each protocol) responded differently to the two modes of salbutamol administration. Both patients exhibited a bronchodilatory response only when the drug was administered with volume control. This, however, does not necessarily mean that the flow/ time profile is the main factor underlying the different response. In these patients, when salbutamol was given with pressure control, baseline Rint was considerably lower than that with volume control (figs. 1 and 2). It is possible that salbutamol, against a background of relatively low airway resistance, was not able to reduce Rint further. A similar observation has been made previously [13].

It has been shown, in an in vitro model of mechanical ventilation, that salbutamol delivery with a decelerating

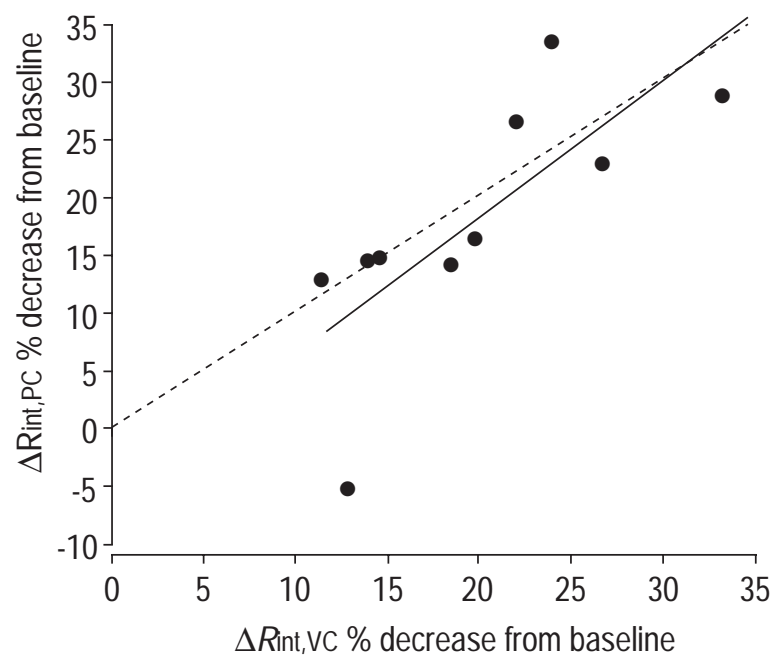

Fig. 4. - Protocol B. Relationship between the mean bronchodilatory response of minimum resistance of the respiratory system (Rint) (\% decrease from baseline) when $600 \mu \mathrm{g}$ salbutamol were given with volume control (Rint,VC) and pressure control (Rint,PC). The mean bronchodilatory response was obtained by averaging the $R$ int response at 15,30 and 60 min after salbutamol. __ : regression line; - - - -: line of identity $(r=0.75, p<0.05)$. For clarity of presentation, the mean bronchodilatory response was used instead of data at various time intervals after drug administration. The significant linear relationships did not change when all data were pooled. $\Delta$ : change in.

inspiratory flow pattern profile was increased by $20 \%$ from that given with a square wave [12]. Thus, although drug delivery to the lower respiratory tract was not measured in the present study, it is likely that the administration of salbutamol with pressure control is associated with increased drug delivery. The reasons why this enhancement was not associated with additional bronchodilation are not entirely clear. Maximal or near-maximal bronchodilation may be achieved in patients receiving controlled mechanical ventilation when $\geq 200 \mu \mathrm{g}$ salbutamol is administered with a high volume spacer, a $V \mathrm{~T}$ of $\sim 500 \mathrm{~mL}$ and MDI actuation synchronized with inspiratory flow. It is likely that, under these circumstances, the inspiratory flow/time profile does not represent a critical factor for bronchodilation.

DHAND et al. [3] have shown, in mechanically ventilated patients with COPD, that the decrease in airway resistance with four puffs salbutamol $\left(90 \mathrm{mg} \cdot\right.$ puff $\left.^{-1}\right)$ was comparable to that observed with cumulative doses of 28 puffs [3]. The findings of DHAND et al. [3] were extended in the present study by showing that significant bronchodilation might be achieved even after $200 \mu \mathrm{g}$ salbutamol. However, this relatively low dose of salbutamol may decrease the duration of bronchodilation, and, in some patients, it may not be able to induce significant bronchodilation. For example, it is not known whether the patient who did not respond to salbutamol in protocol A (fig. 1) would respond to a higher dose of the drug.

In summary, this study demonstrates, in mechanically ventilated patients with acute exacerbation of chronic obstructive pulmonary disease, that salbutamol given via metered-dose inhaler and spacer device induces significant bronchodilation lasting $60 \mathrm{~min}$. The response was evident even after $200 \mu \mathrm{g}$ salbutamol. The manipulation of bronchodilation was not affected by the flow/time profile during drug administration. Thus these results do not favour 
the routine manipulation of flow/time profile when bronchodilators are administered in passively ventilated patients with obstructive pulmonary disease. Provided that $\geq 200 \mu \mathrm{g}$ salbutamol is given and the technique of administration is proper (use of spacer with high volume, and actuation at the beginning of inspiration) significant bronchodilation may be achieved without modification of the ventilator settings.

\section{References}

1. Fernandez A, Lazaro A, Garcia A, Aragon C, Cerda E. Bronchodilators in patients with chronic obstructive pulmonary disease on mechanical ventilation: utilization of metered-dose inhalers. Am Rev Respir Dis 1990; 141: 164-168.

2. Dhand R, Jubran A, Tobin MJ. Bronchodilator delivery by metered-dose inhaler in ventilator supported patients. Am J Respir Crit Care Med 1995; 151: 1827-1833.

3. Dhand R, Duarte AG, Jubran A, et al. Dose-response to bronchodilator delivered by metered-dose inhaler in ventilator-supported patients. Am J Respir Crit Care Med 1996; 154: 388-393.

4. Dhand R, Tobin MJ. Bronchodilator delivery with metered dose inhalers in mechanically ventilated patients. Eur Respir J 1996; 9: 585-595.

5. Dhand R, Tobin MJ. Inhaled bronchodilator therapy in mechanically ventilated patients. Am J Respir Crit Care Med 1997; 156: 3-10.

6. Manthous CA, Hall JB, Schmidt GA, Wood LDH. Metered dose inhaler versus nebulized albuterol in mechanically ventilated patients. Am Rev Respir Dis 1993; 148: 1567-1570.

7. Summer W, Elston R, Tharpe L, Nelson S, Haponik EH. Aerosol bronchodilator delivery methods: relative impact on pulmonary function and cost of respiratory care. Arch Intern Med 1989; 19: 618-623.

8. Bowton DL, Goldsmith WM, Haponik EF. Substitution of metered-dose inhalers for hand nebulizers: success and cost-savings in a large, acute care hospital. Chest 1992; 101: 305-308.

9. Alvine GF, Rodgers P, Fitzsimmons KM, Ahrens RC. Disposable jet nebulizers; how reliable are they? Chest 1992; 101: 316-319.
10. Hamill RJ, Houston ED, Georghiu PR, et al. An outbreak of Burkholderia (formerly Pseudomonas) cepacia respiratory tract colonisation and infection associated with nebulized albuterol therapy. Ann Intern Med 1995; 122: 762-766.

11. Fink JB, Dhand R, Grychowski J, Fahey PJ, Tobin MJ. Reconciling in vitro and in vivo measurements of aerosol delivery from a metered-dose inhaler during mechanical ventilation and defining efficiency-enhancing factors. $\mathrm{Am}$ J Respir Crit Care Med 1999; 159: 63-68.

12. Fink JB, Dhand R, Duarte AG, Jenne JW, Tobin MJ. Deposition of aerosol from metered-dose inhaler during mechanical ventilation: an in vitro model. Am J Respir Crit Care Med 1996; 154: 382-387.

13. Mouloudi E, Katsanoulas K, Anastasaki M, Askitopoulou E, Georgopoulos D. Bronchodilator delivery by metereddose inhaler in mechanically ventilated COPD patients: influence of end-inspiratory pause. Eur Respir J 1998; 12: 165-169.

14. Mouloudi E, Katsanoulas K, Anastasaki M, Hoing S, Georgopoulos D. Bronchodilator delivery by metereddose inhaler in mechanically ventilated COPD patients: influence of tidal volume. Intensive Care Med 1999; 25: 1215-1221.

15. Siafakas NM, Vermeire P, Pride NB, et al., on behalf of the Task Force. Optimal assessment and management of chronic obstructive pulmonary disease. ERS - Consensus statement. Eur Respir J 1995; 8: 1398-1420.

16. Prechter CG, Nelson SB, Hubmayr RD. The ventilatory recruitment threshold for carbon dioxide. Am Rev Respir Dis 1990; 141: 758-764.

17. Gottfried SB, Rossi A, Higgs BD, Zocchi L, Grassino A, Milic-Emili J. Respiratory mechanics in mechanically ventilated patients with respiratory failure. J Appl Physiol 1985; 58: 1849-1858.

18. Bates JHT, Rossi A, Milic-Emili J. Analysis of the behaviour of the respiratory system with constant inspiratory flow. J Appl Physiol 1985; 58: 1840-1848.

19. Kochi T, Okubo S, Zin WA, Milic-Emili J. Flow and volume dependence of pulmonary mechanics in anaesthetized cats. J Appl Physiol 1988; 64: 441-450.

20. Albert RK, Martin TR, Lewis SW. Controlled clinical trial of methylpdnisolone in patients with chronic bronchitis and acute respiratory insufficiency. Ann Intern Med 1980; 92: 753-758. 